\title{
STRUCTURE AND PROPORTIONS OF THE SPERMACETI ORGAN IN THE SPERM WHALE
}

\author{
MALCOLM R. CLARKE \\ The Laboratory, Marine Biological Association, Citadel Hill, Plymouth
}

(Plates I-II, Figs. 1-9)

\begin{abstract}
As a basis for understanding the function of the spermaceti organ of the sperm whale, Physeter macrocephalus L., details of the structure and proportions of the head, skin, blubber and lungs of the adult whale are described.
\end{abstract}

\section{INTRODUCTION}

The head of the sperm whale (Physeter macrocephalus L.), which is largely snout and the crest of the skull necessary to support it, may exceed a third of the total weight and a quarter of the length of the whale. This indicates the snout has an extremely important function but few theories regarding its function take into account the overall structure, whilst the detailed structure and proportions of the adult's snout have been almost totally neglected. Similarly, consideration of the thermal properties of the spermaceti oil, which is the most remarkable component and constitutes a large proportion of the head, have been neglected in studies of function.

In 1970 the author suggested that the spermaceti organ and related structures provided the whale with a means to control its buoyancy by altering the temperature and, hence, the density of the spermaceti oil (Clarke, 1970). This paper gives a detailed description of the structure and proportions of the sperm whale and its head which have relevance to an understanding of its buoyancy function. A second paper (Clarke, 1978a) deals with certain physical properties of the oil pertinent to this hypothesis. A third paper discusses the whale's buoyancy throughout its geographical and depth ranges, showing how the whale may use the spermaceti organ to make itself neutrally buoyant during deep diving over its entire geographical range (Clarke, 1978b).

Many functions have been suggested for the spermaceti organ but usually little account has been taken of detailed structure of the head or physical properties of the oil. The main suggestions of function are sound production (Evans \& Prescott, 1972 ; Norris \& Harvey, 1972; Norris, 1975; Bel'kovich \& Yablokov according to Berzin, 1972; Berzin, 1972), movement of air between the lungs and the nares at depth (Raven \& Gregory, 1933; Sleptzov, 1948, 1952, according to Berzin, 1972; Schenkkan \& Purves, 1973), control of closure of the nasal passages (Kleinenberg \& Yablokov, 1958, according to Berzin, 1972), absorption of nitrogen under pressure (Schenkkan \& Purves, 1973) and a means of attack and defence (Sleptzov, 1952, after Berzin, 1972). A review of the work of USSR scientists is given by Berzin (1972) and a review of work on sonar in Cetacea in general is given by Norris (1975).

As the spermaceti organ may have more than one function and as none of the above 
proposed functions prevent the organ from being used for buoyancy control, they will not be discussed in detail here. Where another proposed function may modify the mode of operation of the buoyancy mechanism it is discussed in Clarke (1978b).

The author formulated the hypothesis that the spermaceti organ controlled buoyancy after employment as a whaling inspector on the Fl. F. 'Southern Harvester' in the Antarctic season of $1955^{-6}$ and visits to whaling stations in Norway (1957) and Madeira (1959). To investigate the problem further, more details of head structure, relative dimensions, temperature and buoyancy of the whale at the sea surface were required as well as freshly collected, deep-frozen spermaceti oil. These collections and observations were made during a 2-month visit to the Union Whaling Co. station at Durban in South Africa. While the great bulk of the whales makes their study extremely difficult and fewer measurements were obtained than one would hope for, the extra details and collections resulting from the visit clarify and fully corroborate the hypothesis regarding the function of the spermaceti organ and related structures. The general form of the components of the head was established by Pouchet \& Beauregard $(1889)$ and Beddard $(1915,1919)$ from the study of foetuses. Raven \& Gregory (1933) described an $18 \mathrm{ft}(5.5 \mathrm{~m})$ male in general outline. Clarke (1970) gave a more detailed drawing of an adult sperm whale which showed the relative sizes of the components and that the 'junk', or lower half of the spermaceti tissue, was divided into blocks. Recently, Berzin (1972, fig. 65, p. 110) erroneously showed the junk undivided but the spermaceti sac divided. Schenkkan \& Purves (1973) figured the head of a $150 \mathrm{~cm}$ foetus and discussed the homologies of its structure and something of its possible function but, except for musculature, gave little more detail than Raven and Gregory or previous workers.

Here, by examining several foetuses, cross-sections of the head of an adult and by the close examination of many adults, the structure and relative proportions of the head of the adult sperm whale is described in much more detail than hitherto.

\section{METHODS}

Measurements of the dimensions of various organs were made with a measuring tape in feet and inches which were later converted to metric equivalents, or with a Wild $\mathrm{M}_{5}$ microscope and graticule as appropriate.

The heads of four foetal whales were collected and preserved in formal saline. Two were sectioned on a bacon slicer and two were dissected and all have been used to elucidate certain details of structure not confirmed in the adult whale.

The names of structural elements employed here are mainly the same as those used by Schenkkan \& Purves (1973).

\section{OBSERVATIONS}

The relative proportions of the organs of the head change dramatically during growth (Figs. 1, 2), and any consideration of the function must be based upon the size and relationships of organs in the adult whale rather than in the foetus. To this end, many measurements were made on four whales and have permitted a reconstruction of the relative sizes of the organs of the snout and of the blubber in adult whales. In addition, details of structure and histology, which have not previously been published but are relevant to a functional study, are described. 


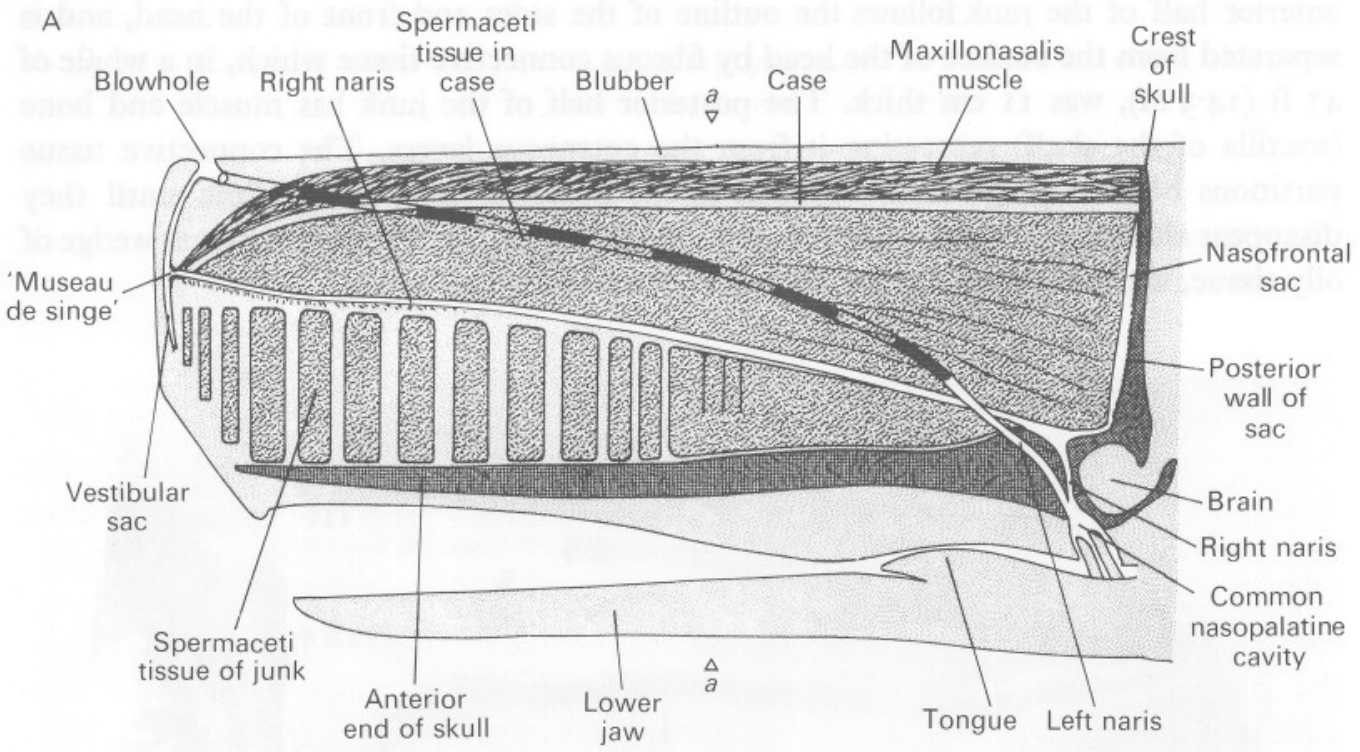

B

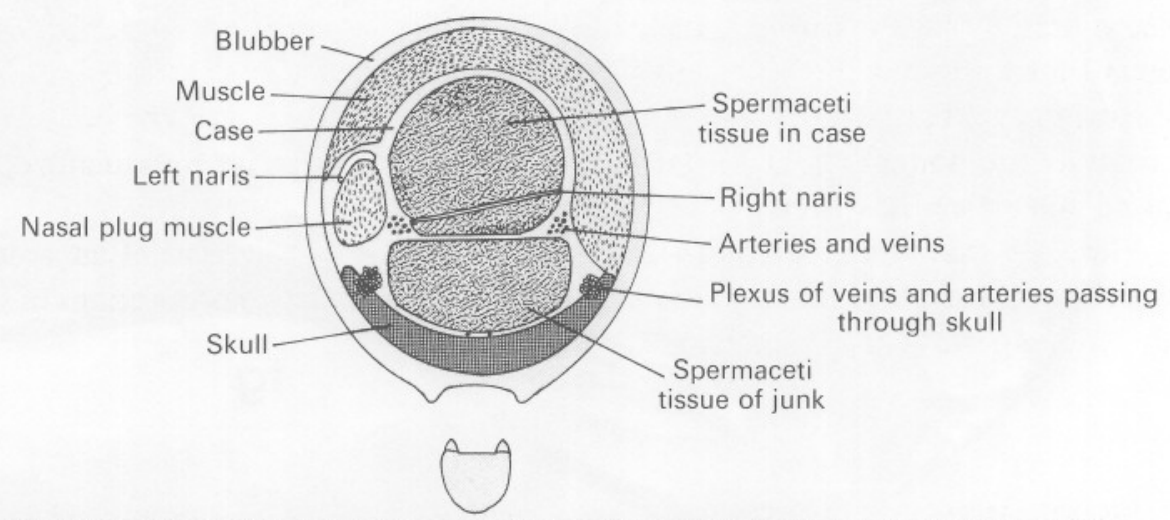

Fig. 1. Diagrammatic sagittal (A) and transverse (B) sections of the head of a sperm whale adult. The blow-hole and the left naris are shown although they would be to the left of a true sagittal section. Transverse section is taken on line $a-a$.

\section{Spermaceti oil}

The snout contains very large quantities of spermaceti oil arranged in two ways. The so-called spermaceti sac is a large, longitudinal, semi-bullet-shaped block of oily tissue enclosed above and laterally by an extremely tough, fibrous case (Fig. 1). Its ventral, flattened side is limited by connective tissue at the anterior end and posteriorly by a diverticulum of the right naris, the nasofrontal sac. The rest of the spermaceti oil is arranged in a series of rectilinear trapezoid blocks of tissue separated by tough, fibrous connective tissue (Fig. 1). An outline joining the corners of all the blocks has roughly the shape of a coffin, with the widest and deepest block being about $10-25 \%$ of the length from the anterior end. The blocks are as broad as their height dorsally and narrow ventrally. This region of the snout with blocks of fat is termed the junk. The 
anterior half of the junk follows the outline of the sides and front of the head, and is separated from the surface of the head by fibrous connective tissue which, in a whale of $47 \mathrm{ft}(14.3 \mathrm{~m})$, was $11 \mathrm{~cm}$ thick. The posterior half of the junk has muscle and bone (maxilla of the skull) separating it from the cutaneous layers. The connective tissue partitions become progressively thinner in the posterior half of the junk until they disappear altogether, so that more than a third of the length of the junk is a great wedge of oily tissue, almost lacking fibrous connective tissue (Fig. 1).

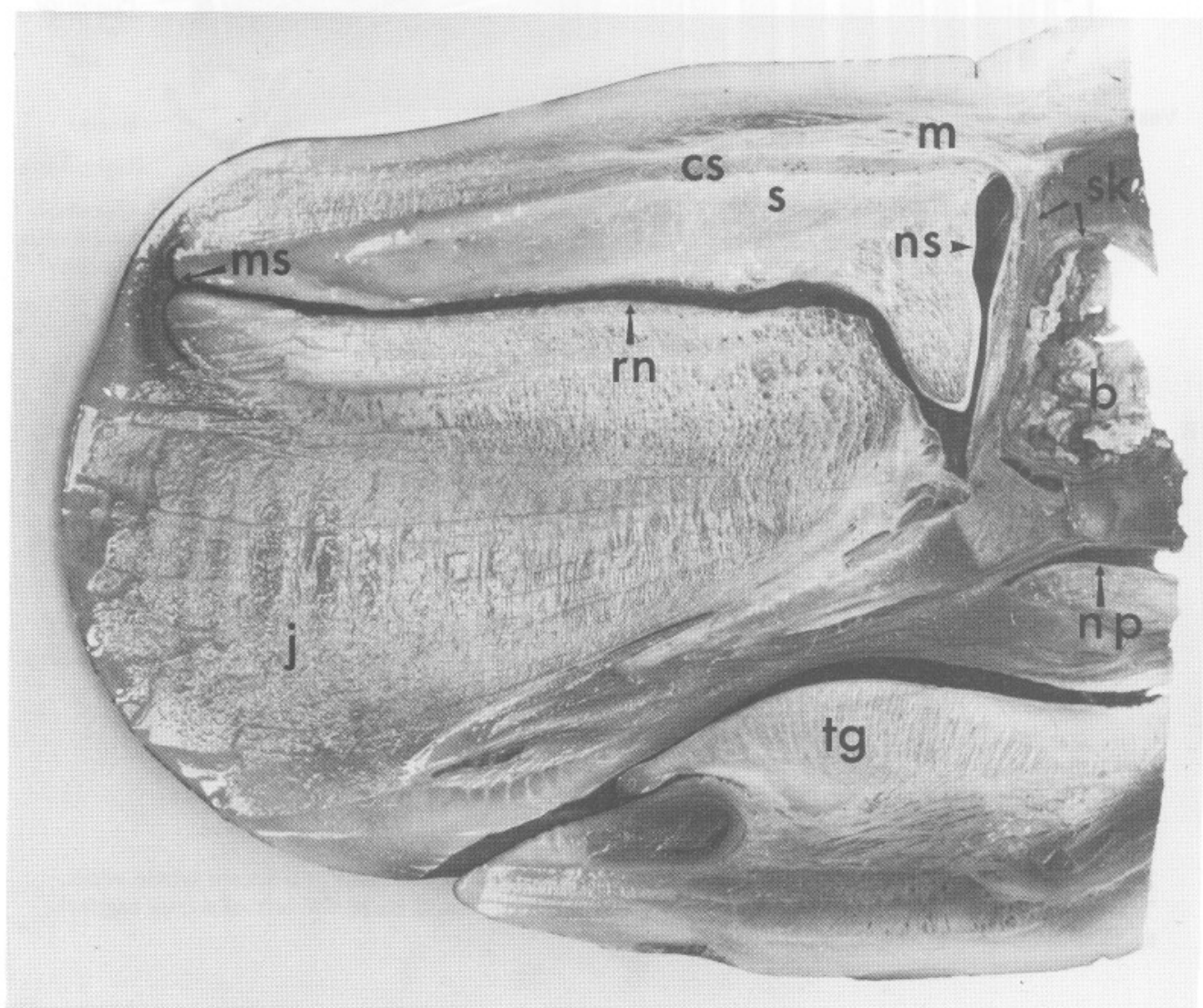

Fig. 2. Sagittal section of the head of a foetus approximately $1 \mathrm{~m}$ in length. b, Brain; cs, case; $\mathrm{j}$, junk; m, muscle; ms, museau de singe; np, nasopalatine cavity; ns, nasofrontal sac; $\mathrm{rn}$, right naris; s, spermaceti sac; sk, skull; tg, tongue.

The spermaceti oil tissue consists of a capillary network (Fig. 3) and, presumably, cells completely filled with oil. However, the walls of these could not be distinguished from flattened capillaries in fresh sections, and their presence is only presumed because the fat does not run out of the tissue unless it is slightly pressed. By weighing the intact, unpressed tissue and then weighing it after it has been thoroughly squeezed in the hand it was possible to estimate the percentage of the tissue which was oil. For $504 \mathrm{~g}$ of tissue freshly removed from the spermaceti organ nearly $98.8 \%$ was oil, although a little blood 
was probably also included. This was not sufficient to settle from the oil when left some hours. For $565 \mathrm{~g}$ of tissue freshly removed from the junk, $98.5 \%$ was oil and blood. These percentages compare with $86.4 \%$ oil and blood in blubber extracted with difficulty by mincing and pressing. The tissue of the posterior wedge of the junk differed by being sticky to the touch and, when squeezed, mucilaginous-like 'strings' of oil ran out.

The weight of the spermaceti oil in a whale can be calculated in several ways. Omura (1950) gave weights of spermaceti for 13 sperm whales from waters adjacent to Japan and a logarithmic plot of these against body weight is given in Fig. 4A.

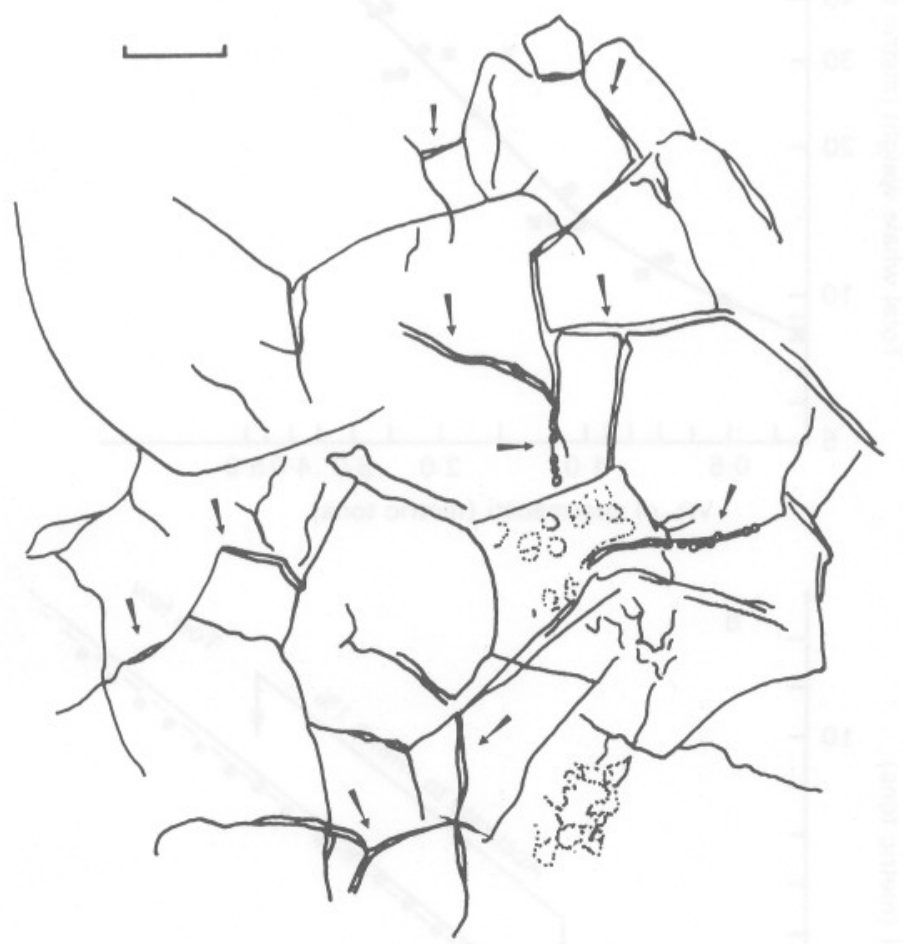

Fig. 3. A camera-lucida drawing of the spermaceti tissue of the sac immediately after collection. Scale, $0.1 \mathrm{~mm}$. Arrows indicate identified capillaries.

A second estimate was made by the author for five whales at Durban by measuring the circumference and length of the inside of the case to obtain the volume of the spermaceti organ and adding this to a calculation of the volume of the junk spermaceti based upon measurements of every block of fat. Values for these whales agreed closely with Omura's data (Fig. 4). The author's in situ measurements, involving no cutting out of the fat with consequent loss, are probably reliable.

Oil production figures show that $11 \%$ of the total oil produced is spermaceti wax. This can be used with Omura's figures relating weight to length and Durban's production estimates relating length to oil production to give an estimate of spermaceti wax (Fig. $4 \mathrm{~B})$. This gives considerably lower estimates for spermaceti than the other two methods 
because it refers to commercially extracted wax which only represents a proportion of the 'natural' spermaceti oil present in the whale's head. Calculations must be based upon the naturally occurring oil because it is the latter which is important to the whale and is investigated here. In the author's earlier outline of the hypothesis on the function of the head (Clarke, 1970) he used a conservative value for the weight of spermaceti in a 31tonne whale; this was half-way between the curve for commercial spermaceti and
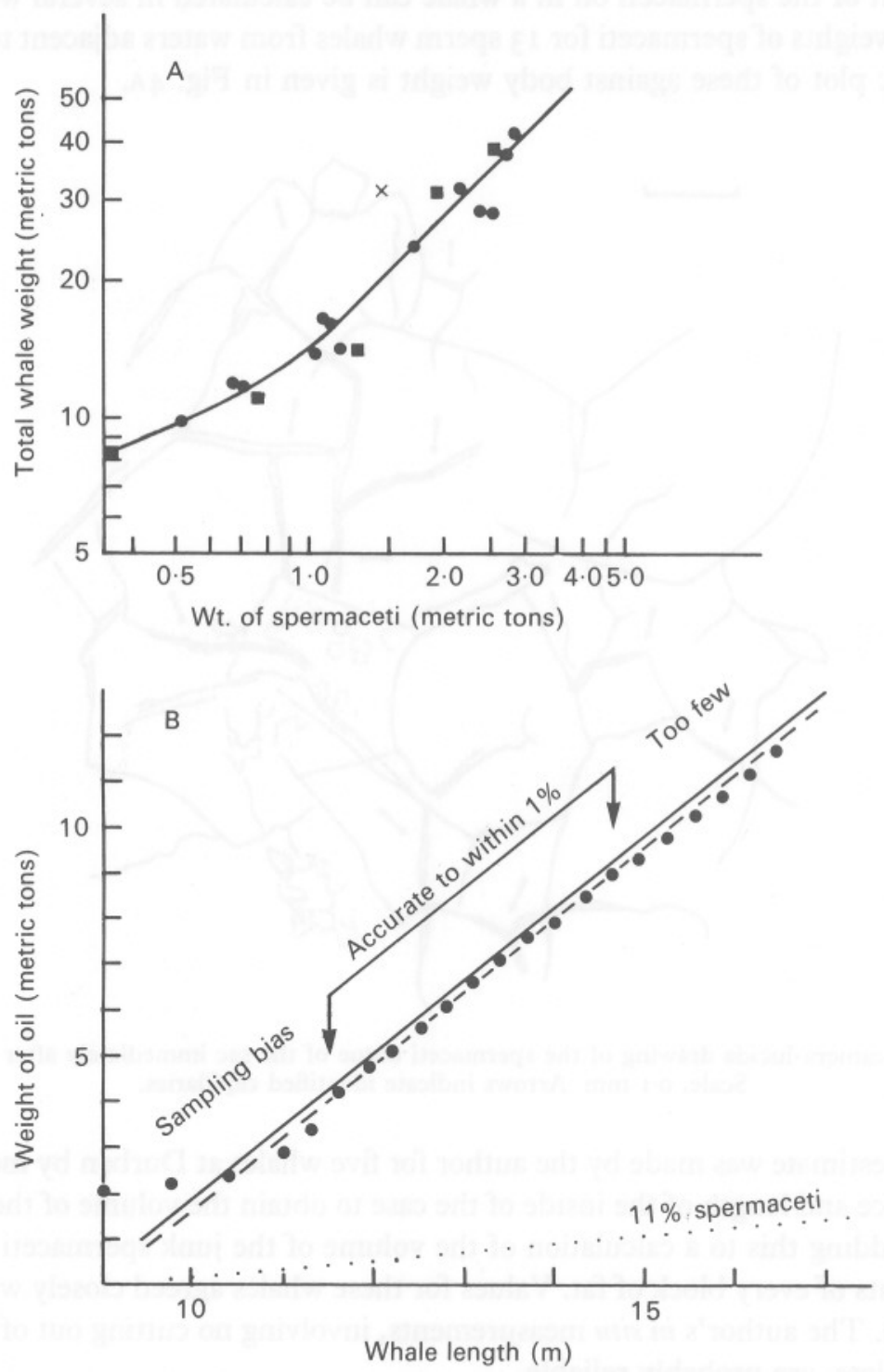

Fig. 4. (A) The weight of the whale plotted against the total weight of the spermaceti oil. Circles, from Omura (1950); squares, estimates based upon measurements made at Durban in 1969; cross, a conservative estimate used by Clarke (1970). (B) Weight of oil commercially extracted from sperm whales of different lengths at Durban prior to 1969. The solid line includes oil in the meat meal extract. The dotted line shows the weight of commercial spermaceti oil extracted assuming $11 \%$ of all oil is pure spermaceti oil. Data of Fig. 4 B kindly provided by Mr J. MacDonald. 
Omura's curve. However, this value proves to be an underestimate in the light of a fuller examination of the problem and a value from Omura's curve is used below.

\section{Nares}

The nasal passages are asymmetrical in arrangement (Figs. 1, 5). The nostrils become joined during early foetal growth (Berzin 1972, p. 106) to form a blow-hole which lies to the left of the anterior end of the dorsal side of the snout, and assumes an S shape. Within the blow-hole there is a small vestibule into which the left and right nares open on the posterior and anterior sides respectively. The left naris runs obliquely through the

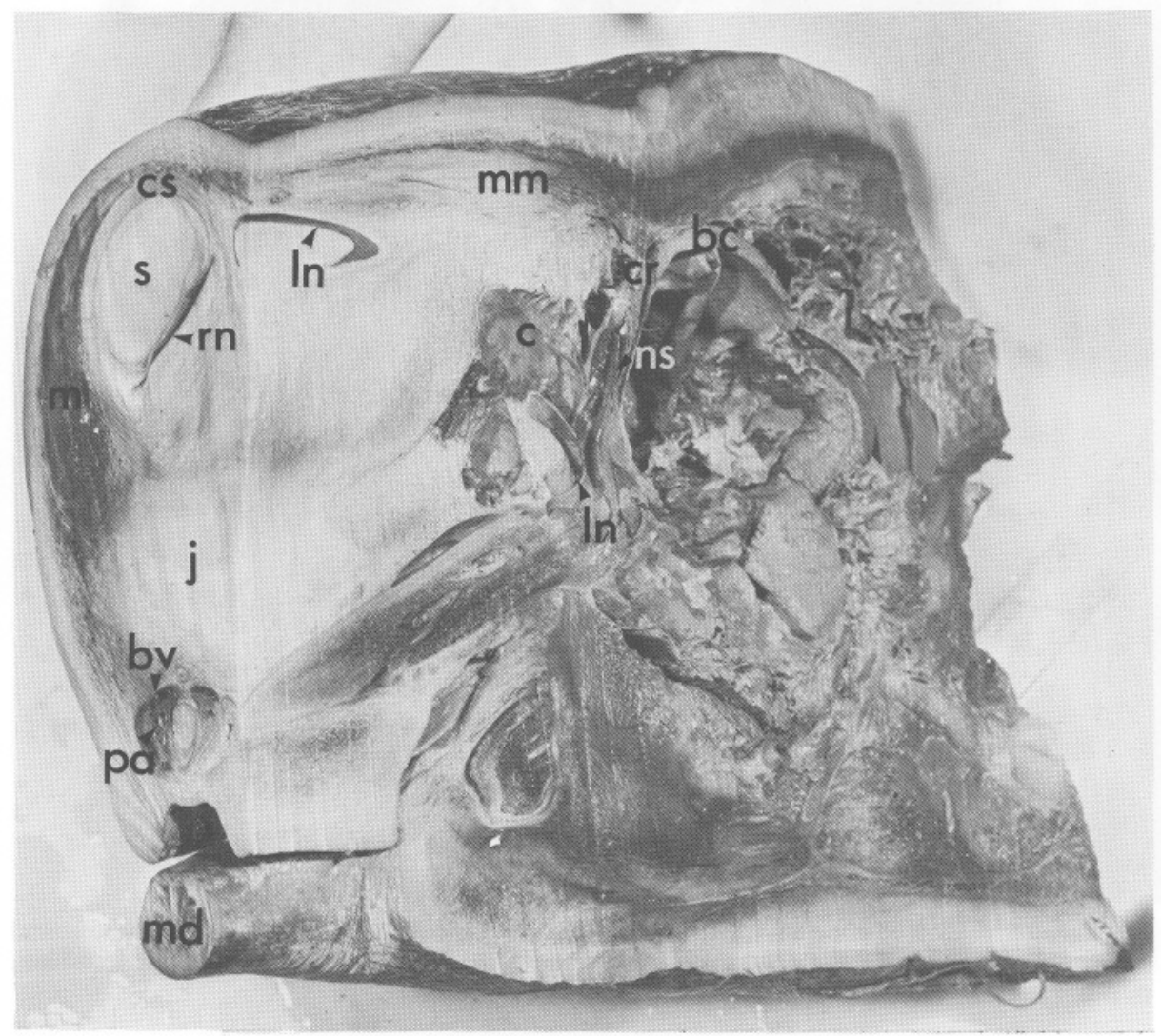

Fig. 5. Posterior end of the head of a foetus to show part of transverse and longitudinal sections. bc, Brain case; bv, blood vessels; c, cavity arising from left naris; cr, crest of skull; cs, case; $\mathrm{j}$, junk; ln, left naris; $\mathrm{m}$, muscle; md, mandible; $\mathrm{mm}$, maxillonasalis muscle; ns, nasofrontal sac; pa, premaxilla; rn, right naris; s, sac.

snout passing in a curve round the outside of the spermaceti case to an opening in the skull at the posterior end of the premaxilla. In transverse section this naris is crescentshaped when relaxed (Fig. 5) with the inner side of the crescent filled with a strong nasal plug muscle. The muscle fibres are inserted in the wall of the left naris at their dorsal ends and into the fibrous connective tissue on the ventro-lateral side of the spermaceti 


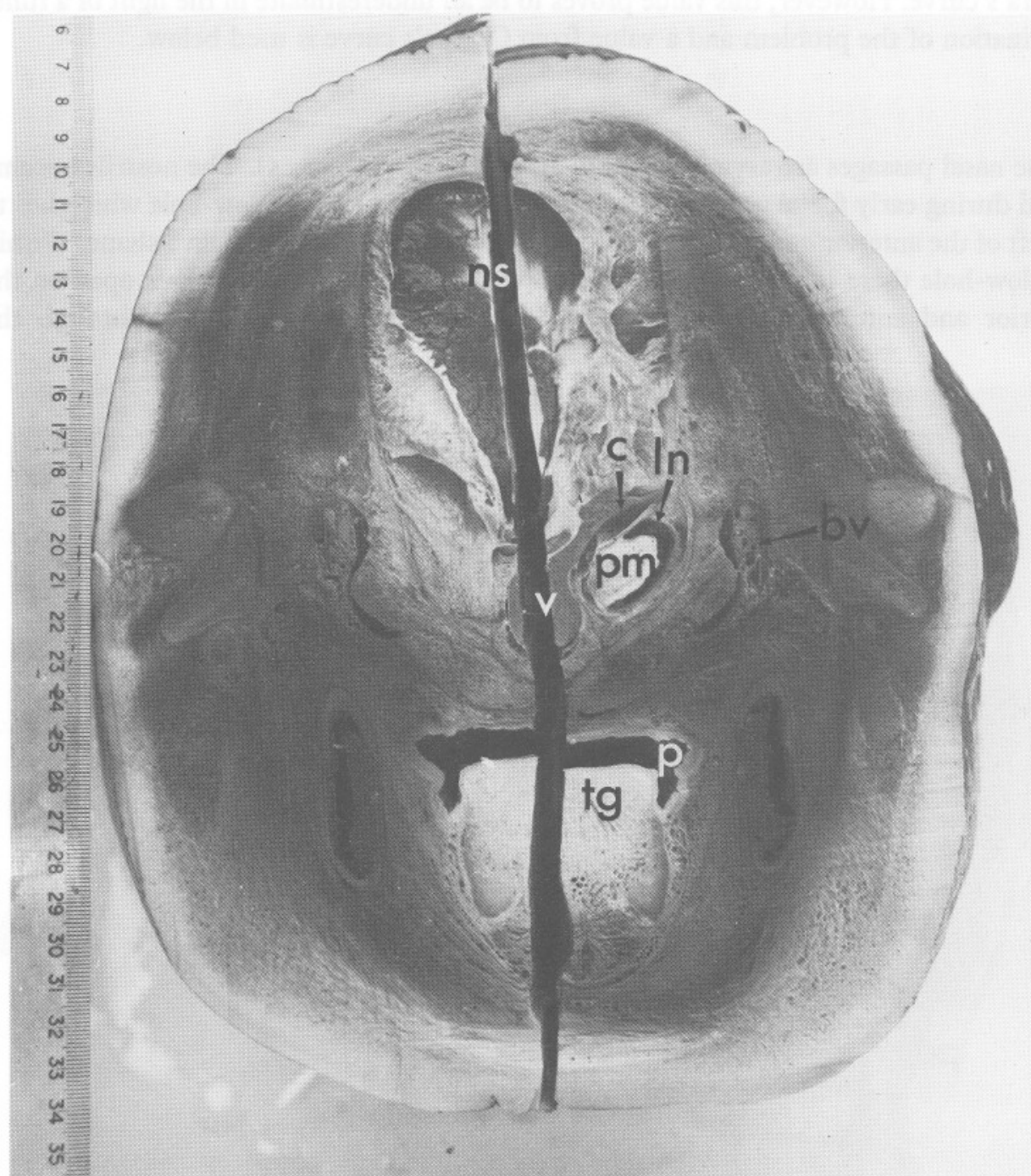

Fig. 6. Anterior surface of a transverse section of the head of a foetus at the level of the nasofrontal sac. bv, Plexus of blood vessels; c, cavity arising from left naris; $\mathrm{ln}$, left naris; ns, nasofrontal sac; $\mathrm{p}$, pharynx; pm, plug muscle; tg, tongue; $\mathrm{v}$, cartilaginous vomer.

sac (Fig. 1). Their contraction expands the left naris which forms a circle in transverse section when expandeci. In the foetal head (Fig. 6), before entering the skull and at a point lying just posterior to the jaw angle, the left naris passes directly inside and against a great plexus of blood vessels which lies above the maxilla. At the same level along the length of the head (Fig. 6) there are also two cavities, one on the left side of the cartilaginous vomer, and one on the dorsal side of the left premaxilla which broaden in the following sections and join the naris. These offshoots of the left naris were found in all four foetuses, although their size varied and poor preservation prevented their true shape and limits from being determined (Figs. 5, 6). In the foetus, parts of the wall of these 
offshoots lie directly against the plexus of blood vessels above the left maxilla close to their passage through the skull. The posterior end of the nasal plug muscle, opening the left naris, becomes attached to the dorsal side of the crescent-like lumen and reduces in width to form a partition across the naris. The lumen to the left of this partition passes

Table 1. Dimensions of sperm whales measured at Durban in 1969

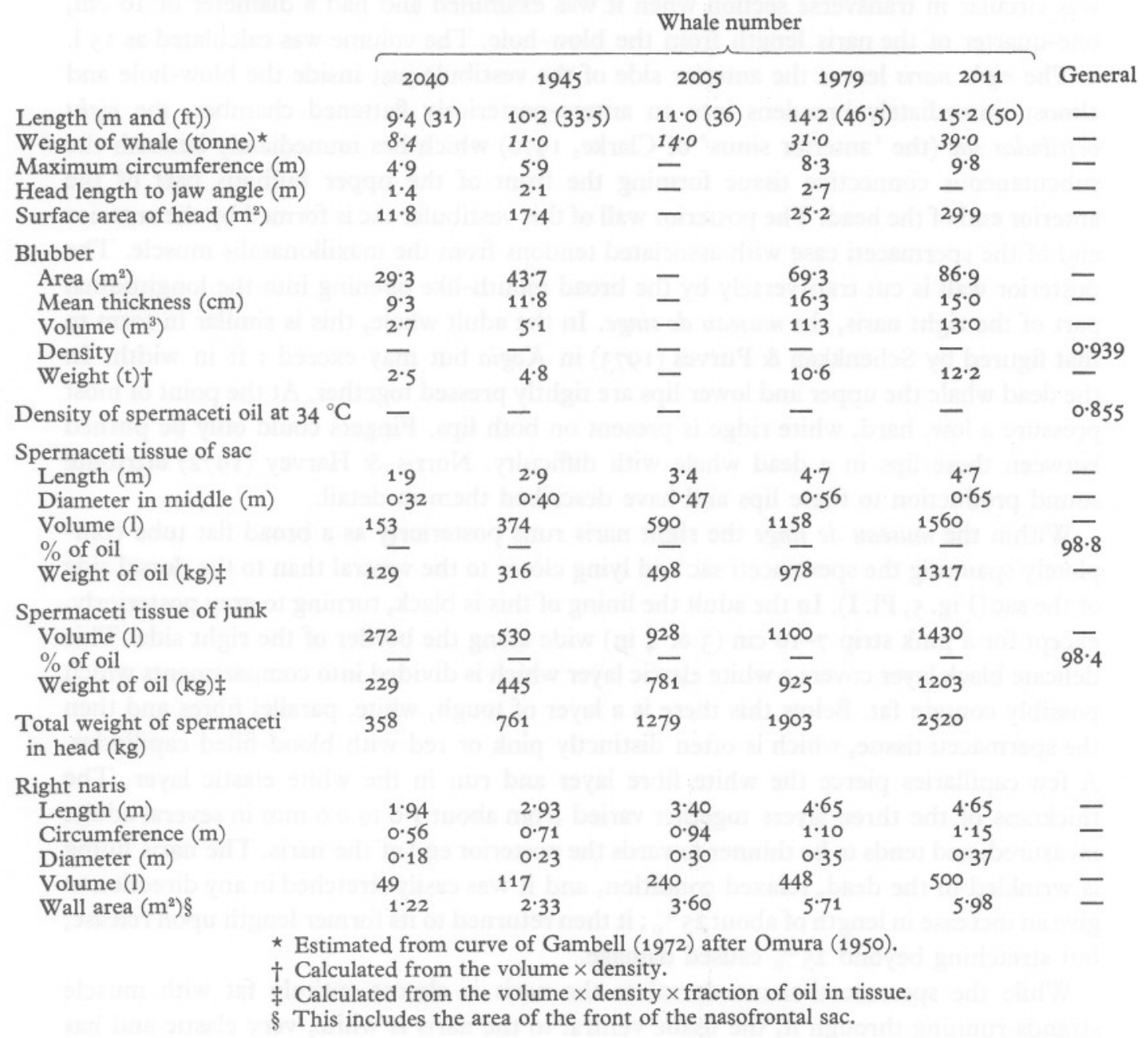

through the skull while that to the right is blind. The presence or extent of the offshoots of the left naris has not been ascertained in the adult but if they are present and lie close to the plexus of blood vessels just above the left maxilla, they may have significance in the overall cooling of the head (Clarke, 1978b).

The lumen of the left naris has a thin, delicate, black lining surrounded by tough connective tissue which is thicker on the inner wall of the crescent into which the nasal plug muscle is inserted. 
The volume of the expanded left naris can be determined from its length and its circumference, assuming it dilates to form a circle in transverse section (Table 1). The circumference of the left naris in a $46 \mathrm{ft} 6$ in $(14.2 \mathrm{~m}$ ) whale (no. 1979) was $52 \mathrm{~cm}$ at a point three-quarters of the naris length from the blow-hole. Taking the left naris as the same length as the spermaceti sac (probably a slight underestimate), the volume of the left naris when dilated would be 1001 . In a $31 \mathrm{ft}(9.4 \mathrm{~m})$ whale (no. 2040) the left naris was circular in transverse section when it was examined and had a diameter of $10 \mathrm{~cm}$, one-quarter of the naris length from the blow-hole. The volume was calculated as $15 \mathrm{l}$.

The right naris leaves the anterior side of the vestibule just inside the blow-hole and almost immediately broadens into an antero-posteriorly flattened chamber, the right vestibular sac (the 'anterior sinus' of Clarke, 1970) which lies immediately beneath the subcutaneous connective tissue forming the front of the upper bulbous part of the anterior end of the head. The posterior wall of this vestibular sac is formed by the anterior end of the spermaceti case with associated tendons from the maxillonasalis muscle. The posterior wall is cut transversely by the broad mouth-like opening into the longitudinal part of the right naris, the museau de singe. In the adult whale, this is similar in form to that figured by Schenkkan \& Purves (1973) in Kogia but may exceed $1 \mathrm{ft}$ in width. In the dead whale the upper and lower lips are tightly pressed together. At the point of most pressure a low, hard, white ridge is present on both lips. Fingers could only be pushed between these lips in a dead whale with difficulty. Norris \& Harvey (1972) attribute sound production to these lips and have described them in detail.

Within the museau de singe the right naris runs posteriorly as a broad flat tube completely spanning the spermaceti sac and lying closer to the ventral than to the dorsal side of the sac (Fig. 5, Pl. I). In the adult the lining of this is black, turning to grey posteriorly, except for a pink strip 7-10 $\mathrm{cm}$ ( 3 or 4 in) wide along the border of the right side. This delicate black layer covers a white elastic layer which is divided into compartments which possibly contain fat. Below this there is a layer of tough, white, parallel fibres and then the spermaceti tissue, which is often distinctly pink or red with blood-filled capillaries. A few capillaries pierce the white fibre layer and run in the white elastic layer. The thickness of the three layers together varied from about 1.0 to $0.6 \mathrm{~mm}$ in several adults measured, and tends to be thinner towards the posterior end of the naris. The naris lining is wrinkled in the dead, relaxed condition, and it was easily stretched in any direction to give an increase in length of about $25 \%$; it then returned to its former length upon release, but stretching beyond $25 \%$ caused damage.

While the spermaceti tissue dorsal to the naris is almost entirely fat with muscle strands running through it, the tissue ventral to the naris is white, very elastic and has dorso-ventral and longitudinal muscle strands running through it (Pl. I). Anteriorly, the longitudinal strands and posteriorly, the dorso-ventral strands, are the most developed. The longitudinal muscles are inserted in the ventral lip of the museau de singe, and their contraction must pull the lip down and back when the lips are opened. The dorsoventral muscles pull the floor of the right naris ventrally. The two sets of muscle, called by Schenkkan \& Purves (1973) the nasal plug muscle, could work in opposition to one another to some extent since they are embedded in the same tissue.

The muscle strands in the spermaceti tissue dorsal to the right naris run down the 
sides of the posterior part of the sac, and then obliquely across the spermaceti tissue towards the anterior face of the nasofrontal sac. Their contraction must pull the anterior wall of this offshoot of the right naris forwards. The nasofrontal sac separates the rear end of the spermaceti sac from the skull. Its anterior face has a lining similar to that of the longitudinal part of the right naris, but its posterior face is covered in bumps each about $1 \mathrm{~cm}$ across (Norris \& Harvey, 1972). If this lining is cut perpendicular to the surface, the bumps are seen to overlie fluid-filled vesicles which lie within smooth white elastic tissue
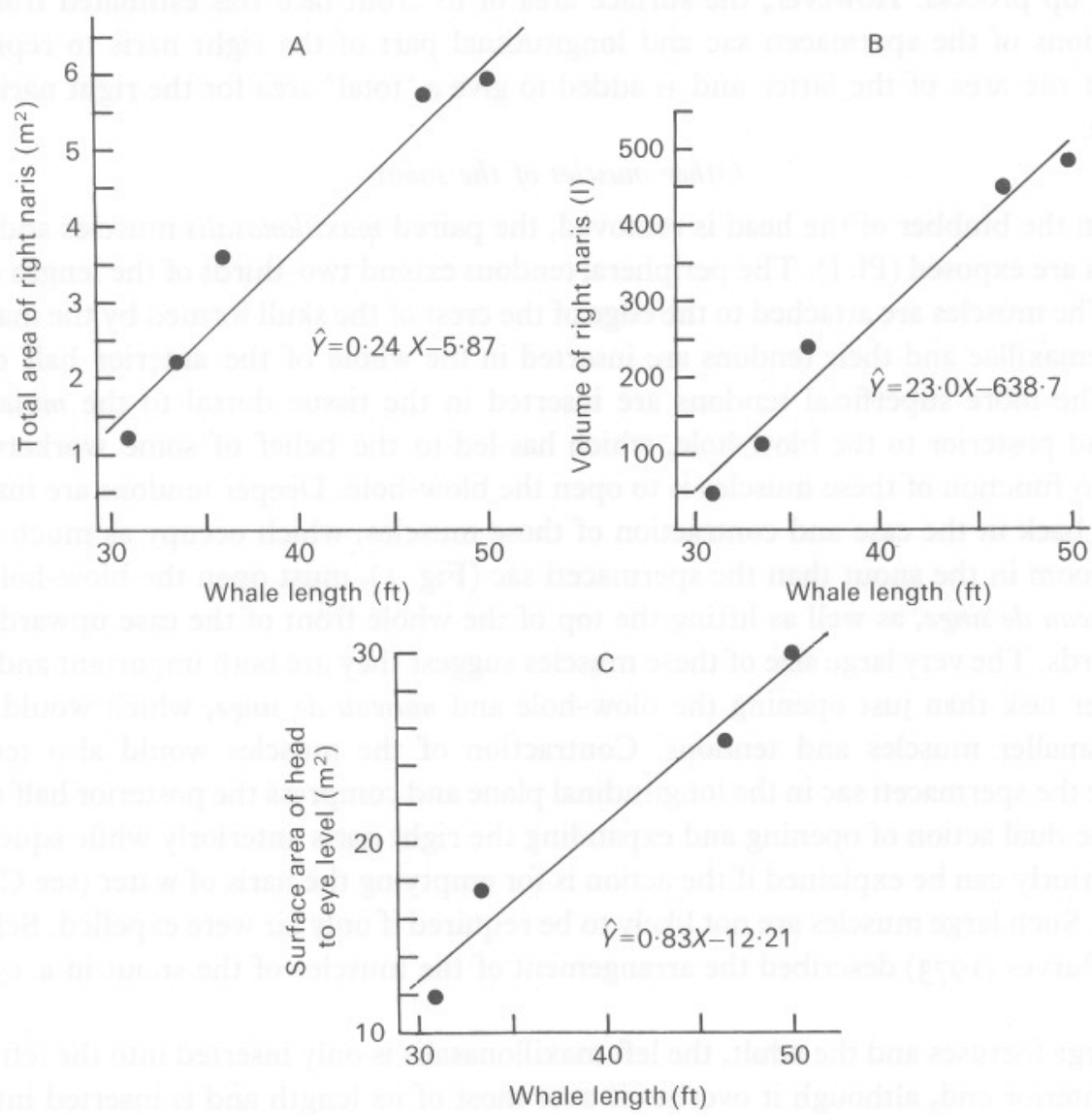

Fig. 7. Surface areas and volumes plotted against whale length. Circles show measurements made at Durban in 1969. Regressions are also shown.

covered by a thin grey layer similar to that lining the longitudinal part of the naris. The fluid is clear and aqueous, and acidified barium chloride gave no precipitate, showing that it is not sea water; it did not taste salty. Only very few blood vessels were present in the white tissue. The nasofrontal sac opens into the dorsal side of the longitudinal part of the right naris, just before it narrows and passes through the skull. Immediately after passing through the skull, it joins the left naris to form the common nasopalatine cavity, into which the larynx fits and is held by a sphincter (Fig. 1). The left naris barely narrows to pass through the skull but the right naris narrows to about $2.5 \mathrm{~cm}$ in diameter in a 
$33 \mathrm{ft}(10.1 \mathrm{~m})$ whale. It appears to be held tightly shut by a sphincter and possibly also a valve.

Dimensions of the right naris were measured in five whales (Table 1). The length was taken as the same as the spermaceti sac. The circumference was measured in the midthird of the naris length so that the gradual widening over the length did not affect the calculation of volume which assumed the shape of a parallel-sided cylinder. The nasofrontal sac was only found in one adult whale because it was usually hidden during the cutting up process. However, the surface area of its front face was estimated from the dimensions of the spermaceti sac and longitudinal part of the right naris to represent $12 \%$ of the area of the latter and is added to give a 'total' area for the right naris wall (Fig. 7).

\section{Other muscles of the snout}

When the blubber of the head is removed, the paired maxillonasalis muscles and their tendons are exposed (Pl. I). The peripheral tendons extend two-thirds of the length of the head. The muscles are attached to the edge of the crest of the skull formed by the maxillae and premaxillae and their tendons are inserted in the whole of the anterior half of the case. The more superficial tendons are inserted in the tissue dorsal to the musea $u$ de singe and posterior to the blow-hole, which has led to the belief of some workers that the main function of these muscles is to open the blow-hole. Deeper tendons are inserted further back in the case and contraction of these muscles, which occupy as much as, or more, room in the snout than the spermaceti sac (Fig. 1), must open the blow-hole and the museau de singe, as well as lifting the top of the whole front of the case upwards and backwards. The very large size of these muscles suggest they are both important and have a greater task than just opening the blow-hole and museau de singe, which would need much smaller muscles and tendons. Contraction of the muscles would also tend to squeeze the spermaceti sac in the longitudinal plane and compress the posterior half of the sac. The dual action of opening and expanding the right naris anteriorly while squeezing it posteriorly can be explained if the action is for emptying the naris of water (see Clarke, $1978 b$ ). Such large muscles are not likely to be required if only air were expelled. Schenkkan \& Purves (1973) described the arrangement of the muscles of the snout in a $150 \mathrm{~cm}$ foetus.

In large foetuses and the adult, the left maxillonasalis is only inserted into the left naris at its anterior end, although it overlies it over most of its length and is inserted into the right naris near the museau de singe. The muscles and tendons of the right side, however, are just as strongly developed, and as noted above, have insertions over much of the anterior half of the case.

\section{Blood supply}

The snout is supplied with blood via the paired internal maxillary arteries which pass through the maxillae of each side, divide into several branches, most of which run forwards in the head in rather fatty connective tissue to the side of the top of the junk (Fig. 8). The first branch of the right internal maxillary artery enters the spermaceti sac near the junction of the nasofrontal sac with the longitudinal part of the right naris. It then divides, one branch extending dorsally to the tissue immediately anterior to the 
nasofrontal sac, and the other anteriorly in the centre of the spermaceti sac. Branches from this maxillary artery supply all the capillaries supporting the spermaceti oil tissue of the sac. The capillaries above the longitudinal part of the right naris tend to run transversely while those anterior to the nasofrontal sac tend to run vertically. Small blood vessels are

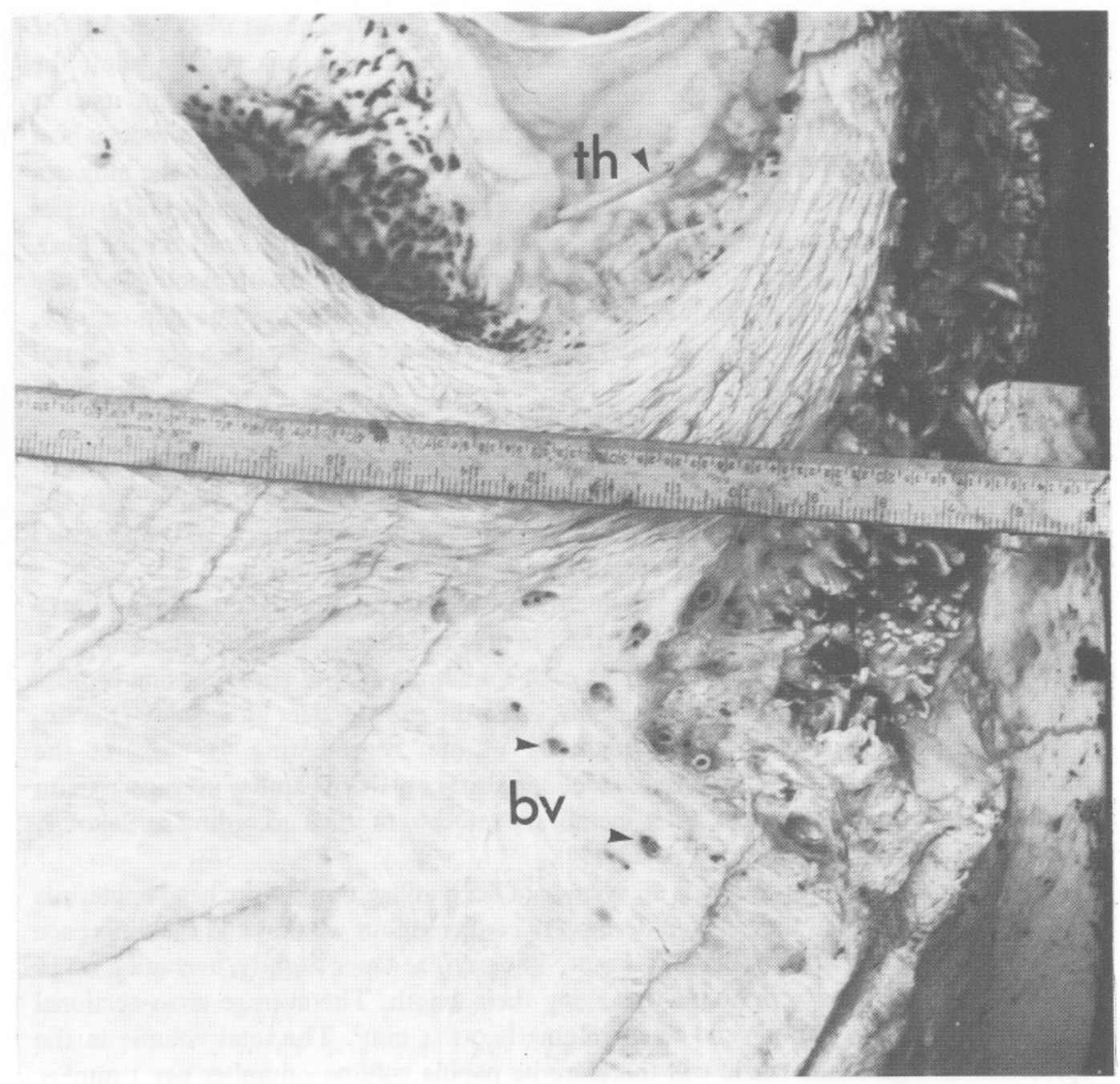

Fig. 8. Transverse section of the region ventro-lateral to the spermaceti sac showing the blood vessels which supply the junk and skin of the head. bv, Blood vessels; th, thermometer inserted into right side of right naris.

also numerous in the ventral wall of the right naris. At the anterior end of the spermaceti sac, blood from the capillaries collects into a few larger vessels which pass through the anterior end of the case. Their precise course after that is not known, but the blood presumably returns via the veins which run back along the head close to the branches of the internal maxillary artery on each side of the junk. Branches of these arteries supply the whole junk and peripheral tissues of the snout and the veins returning the blood lie 
parallel to them. In many cases, an artery and vein lie side by side in their own 'channel' in the fibrous connective tissues (Fig. 8), and above and below the point at which these vessels all pass through the skull the vessels form a rete-like plexus (Figs. 1, 6). A large artery and vein then pass through rete which lie to the sides of the occipital condyles.

Sections of the foetus show that there is a highly vascular layer about $1 \mathrm{~cm}$ beneath the skin covering the anterior end of the snout and the sides of the junk. In the adult the highly vascular layer lies about two inches beneath the skin surface. The skin itself is supplied by large numbers of capillaries, but when these are contracted to reduce heat loss, the blood can still circulate in the deeper layers. Thus, blood coming to the junk can pass either through the skin and be cooled so that it cools the junk and incoming arteries as it returns towards the heart, or it can by-pass the skin so that the head retains heat. Plate II в shows (black) anterior blocks of junk which were distended with blood in a whale which must have been actively losing heat from the tip of the snout at the time of its capture. In the anterior wall of the right vestibular sac, the vessels are orientated in a dorso-ventral direction.

\section{Blubber and skin}

The main features of the epidermis and blubber of the sperm whale have been outlined by Berzin (1972) from work by various Russian scientists (Sleptzov, 1952, etc.). In the present study the main features of interest are the length and numbers of the vascular dermal papillae and the thickness, area and volume of the fatty blubber.

The outer layer of the epidermis is a fine transparent membrane which is easily wiped off. Beneath this, the epidermis is pigmented to give the characteristically black appearance. Straight, finger-like dermal papillae, each containing several anastomosing capillaries, protrude into the pigmented epidermis. According to the data of Sokolov (Berzin, 1972) these papillae have a mean length of $3.5 \mathrm{~mm}$ representing $71-86 \%$ of the thickness of the epidermis. The author's sections also show these papillae average $3.5 \mathrm{~mm}$ in length but may approach the outer membrane (18-45 $\mu \mathrm{m}$ thick according to Sokolov, 1955) even closer than shown by Sokolov.

From horizontal sections there is an average of 8.2 papillae $/ \mathrm{mm}^{2}$ in the head epidermis and 7.4 papillae $/ \mathrm{mm}^{2}$ in the body epidermis ( 18 counts in four whales) and the difference between these is not statistically significant. The papillae taper slightly, averaging 0.136 $\mathrm{mm}$ at the tip and $0.259 \mathrm{~mm}$ half-way along their length. The average cross-sectional area is therefore $0.053 \mathrm{~mm}^{2}$ and their volume is $0.184 \mathrm{~mm}^{3}$. The total volume in the epidermis of a 30-tonne whale will therefore be papilla volume $\times$ number per $1 \mathrm{~mm}^{2} \times$ surface area of the whale (Table 1 ) or $0.184 \times 7.8 \times 69 \bumpeq 1001$. The blood weight is probably about $12 \%$ of the body weight so that about $3 \%$ of the blood could occupy the papillae at one time. The area of blood 'presented to the outside' half-way along the papillae (i.e. only $2.7 \mathrm{~mm}$ from the outside surface) would be over $40 \%$ of the surface of the body; thus, the skin must be an extremely efficient cooling device. Vaso-constriction of the papillae and outer blubber layers can, very probably, withdraw the blood to within the insulating fat layers and cut down heat loss to a minimum. Anastomosing vessels are known to join sub-epidermal arterioles and venules and these are also likely to be present beneath the fatty layer. 
The surface area of the body of four whales (Table 1) was found by measuring the circumference of the whale at a number of points along its length (circles in Fig. 9). The circumference at each point was plotted to scale on graph paper to give outlines of the skin. The areas were then measured. The head was taken as the area in front of the eye. Estimates of tail, flipper, fin and anterior end of the head were added to find the total area of the whale.

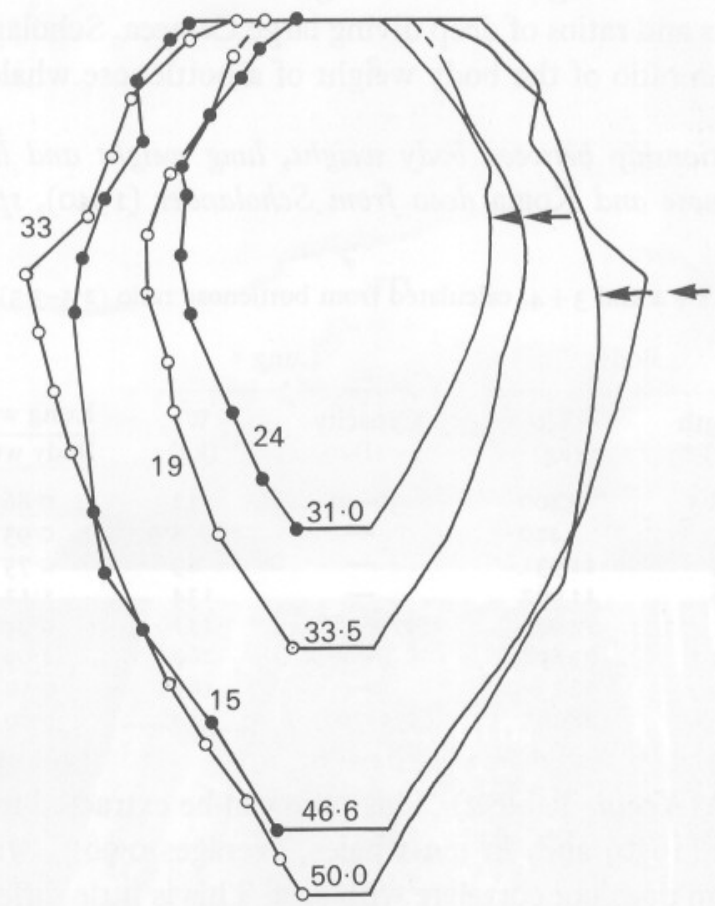

Fig. 9. The outlines of the skin of four whales obtained by measuring the circumference of the whale at each point shown as a circle, plotting these on graph paper, and joining them up to give the outline. The anterior ends are at the top. The positions of the eyes are indicated by arrows. Lengths of the whales are given in feet at the tail ends. Figures show the number of blubber thickness measurements made for each whale.

The thickness of the blubber was measured at recorded locations on one side of each whale. Thicknesses in each $0.6 \mathrm{~m}^{2}$ were then either read from measurements or interpolated, and the mean thickness for the whole whale and the head blubber calculated. The numbers in Fig. 9 show the number of measurements of thickness made for each of the four whales. Volume of the blubber was calculated from the surface area and the mean thickness.

The outside of a sperm whale has a characteristically wrinkled or bumpy appearance which must increase the surface areas above the areas obtained from body circumference measurements (Berzin, 1972). This is difficult to estimate but the folds are predominantly longitudinal and, to judge from photographs, occupy up to $30 \%$ of the body surface.

The folds are sometimes about $10 \mathrm{~cm}$ from crest to crest and the depth probably approaches a quarter of the fold width (from photographs). This would mean the surface 
area would be increased by about $7 \%$ over its 'flat' area. These wrinkles, however, are mainly restricted to the body and do not greatly increase the area of the head surface. They may be to allow reduction in volume of the blubber under pressure (Clarke, 1978b) and have not been taken into account in calculations of surface area.

\section{Lungs}

Few measurements of lung volume of large Cetacea have been made. Table 2 gives some measurements and ratios of deep diving large Cetacea. Scholander (1940) expressed the lung weight as a ratio of the body weight of a bottlenose whale (Hyperoodon) and a

Table 2. The relationship between body weight, lung weight and lung capacity in three Odontocetes: bottlenose and Kogia data from Scholander (1940), sperm whale data from Omura (1950)

Mean lung capacities of $1+2$ and $3+4$, calculated from bottlenose ratio $(2 \cdot 5-3 \cdot 3)$, are shown in parentheses.

\begin{tabular}{|c|c|c|c|c|c|c|}
\hline \multirow[b]{2}{*}{ Species } & \multicolumn{2}{|c|}{ Body } & \multicolumn{2}{|c|}{ Lung } & \multirow[b]{2}{*}{$\frac{\text { Lung wt }}{\text { Body wt }} \times 100$} & \multirow[b]{2}{*}{$\frac{\text { Lung capacity }}{\text { Lung wt }} \times 100$} \\
\hline & $\begin{array}{l}\text { Length } \\
(\mathrm{ft})\end{array}$ & $\begin{array}{l}\mathrm{Wt} \\
(\mathrm{kg})\end{array}$ & $\begin{array}{l}\text { Capacity } \\
\text { (1) }\end{array}$ & $\begin{array}{l}\text { Wt } \\
(\mathrm{kg})\end{array}$ & & \\
\hline Bottlenose & $18 \cdot 5$ & 1400 & $30-40$ & 12 & 0.86 & $2 \cdot 5-3 \cdot 3$ \\
\hline Kogia & & 420 & - & 3.9 & 0.93 & \\
\hline Sperm 1 & 35 & 11931 & - & 89 & 0.75 & \\
\hline Sperm 2 & 36 & 11962 & - & 134 & 1.12 & \\
\hline Mean of 1 and 2 & & 11946 & $(279-368)$ & 111 & 0.94 & \\
\hline Sperm 3 & 44 & 23898 & - & 260 & 1.09 & \\
\hline Sperm 4 & 49 & 32232 & - & 167 & 0.52 & \\
\hline Mean of 3 and 4 & & 28065 & $(535-706)$ & 214 & 0.80 & \\
\hline
\end{tabular}

pigmy sperm whale (Kogia, Table 2). This ratio can be extracted for sperm whales from the data of Omura (1950) and, in ten whales, averages $0.90 \%$ with a range of 0.49 $1.49 \%$; the variation does not correlate with size. This is little different from the $0.86 \%$ for the bottlenose and $0.93 \%$ for the pigmy sperm whale, and we might expect other parameters of the lung to be similar. Scholander measured the lung volume of the bottlenose by pumping it up to the same length as the pleural cavity. If this volume $(30-401)$ is divided by the lung weight $(12 \mathrm{~kg})$, the resulting ratio of $2 \cdot 5-3.3$ can be used to estimate the volume of sperm-whale lungs. From this, a 30 -tonne whale would have a lung volume of 650-858 1 , if the value for the $44 \mathrm{ft}$ whale in Table 2 is taken, or 535-706 1, if the mean value for the two larger whales is taken. In buoyancy calculations (Clarke 1978b), 7001 is taken as the most likely value with limits of $600-8001$. A value of 6001 is close to an extrapolated line including the lung volumes of the well studied Tursiops and measurements of the bottlenose (Scholander, 1940) and Orcinus orca (Spencer, Gornall \& Poulter, 1967). A much larger value of 17001 is obtained if a curve for lung volume plotted against body weight for a wide variety of mammals published by Tenney \& Remmers (1963) is extrapolated.

The author is most grateful to Professor E. J. Denton and Dr Q. Bone for helpful criticism of the manuscript; to Sir George Deacon and Mr P. M. David for their encouragement whilst the author was employed by the Institute of Oceanographic Sciences, Wormley, Surrey, and to Mr S. G. Brown and $\mathrm{Mr} \mathrm{H}$. Roe for two of the photographs (Pl. IIC and A respectively). 

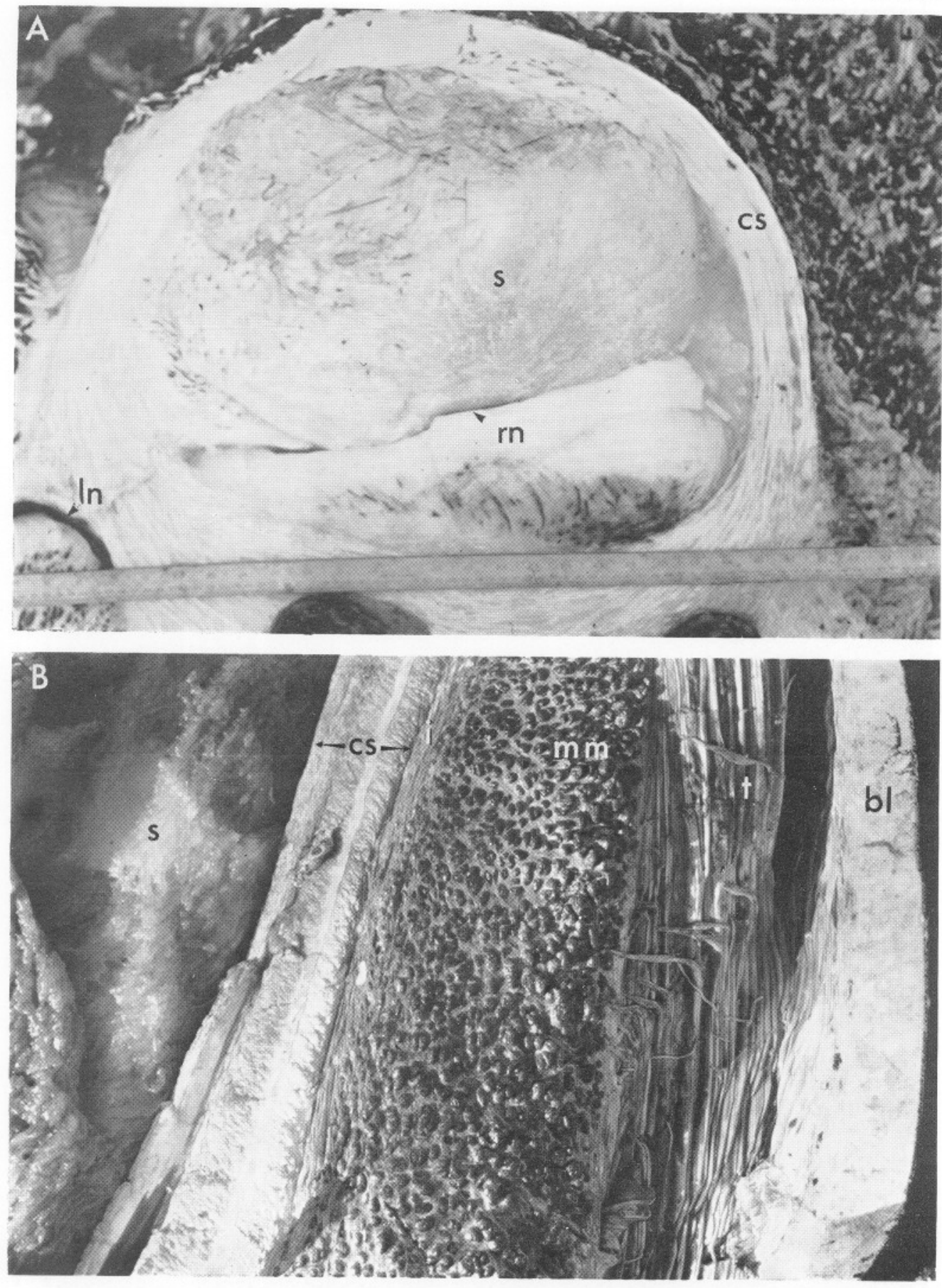

(Facing p. 16) 

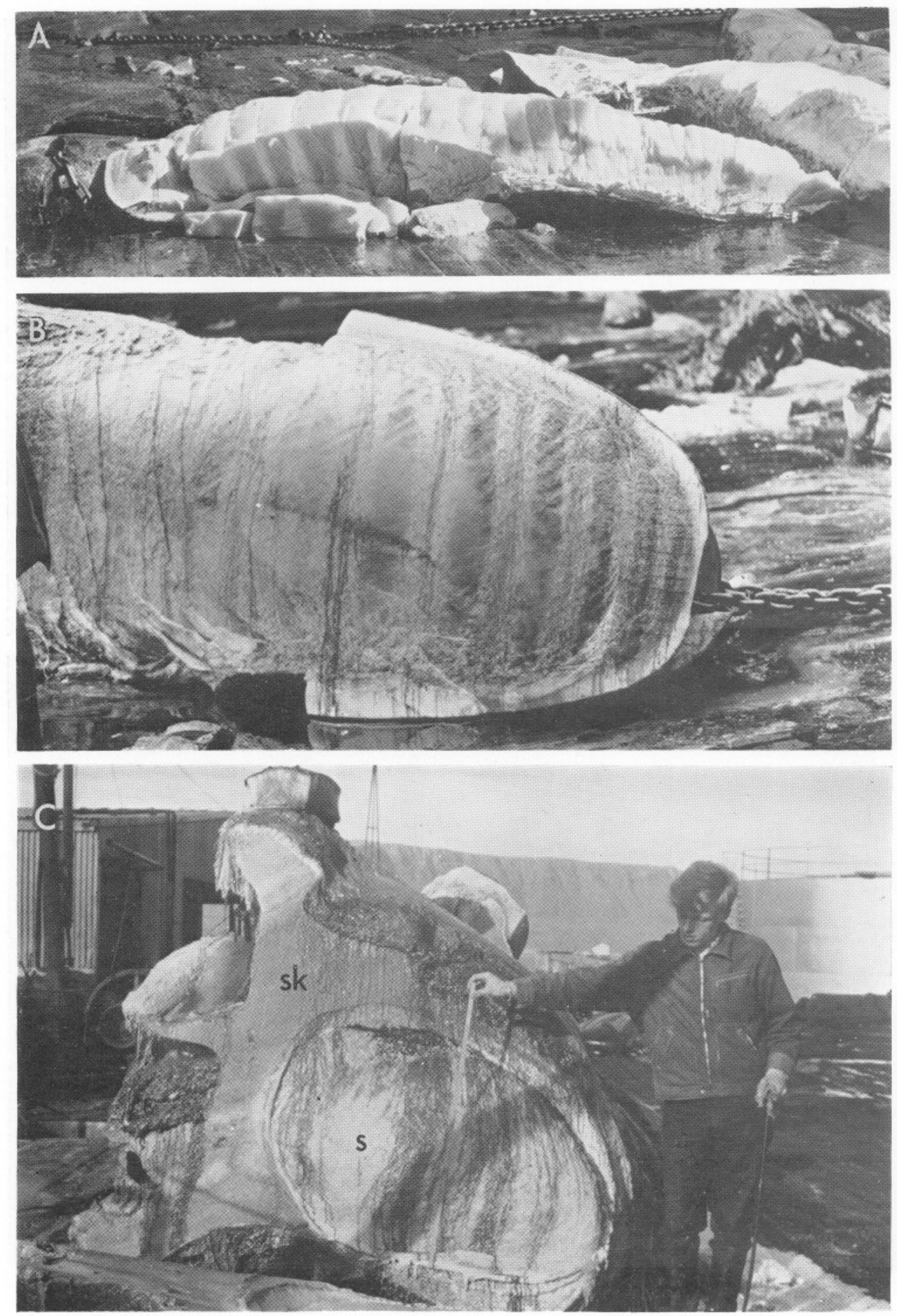


\section{REFERENCES}

BEDDARD, F. E., 1915. Contributions to the knowledge of the anatomy of the sperm whale (Physeter macrocephalus) based upon the examination of a young foetus. Annals of Durban Museum, 1, 107-124.

BEDDARD, F. E., 1919. Further contribution to the anatomy of the sperm whale (Physeter macrocephalus) based upon the examination of two additional foetuses. Annals of Durban Museum, 2, 129-148.

Berzin, A. A., 1972. The Sperm Whale. v, 394 pp. Jerusalem: Israel Program for Scientific Translations Ltd. [Transl. E. Hoz and Z. Blake.]

Clarke, M. R., 1970. The function of the spermaceti organ of the sperm whale. Nature, London, 228, 873-874.

Clarke, M. R., 1978a. Physical properties of spermaceti oil in the sperm whale. fournal of the Marine Biological Association of the United Kingdom, 58, 19-26.

Clarke, M. R., $1978 b$. Buoyancy control as a function of the spermaceti organ in the sperm whale. Fournal of the Marine Biological Association of the United Kingdom, 58, 27-71.

Evans, W. E. \& PrescotT, J. H., 1972. Observations on the sound production capabilities of the bottlenose porpoise: a study of whistles and clicks. Zoologica (New York), 47, 121-128.

NorRIs, K. S., 1975. Cetacean biosonar. 1. Anatomical and behavioural studies. In Biochemical and Biophysical Perpsectives in Marine Biology, vol. 2 (ed. D. C. Malins and J. R. Sargent), pp. 215-236. Academic Press.

NoRRIS, K. S. \& HARVEY, G. W., 1972. A theory for the function of the spermaceti organ of the sperm whale. In Animal Orientation and Navigation. (ed. S. R. Galler, K. Schmidt-Koenig, G. J. Jacobs and R. E. Belleville), 262 pp. NASA Special Publication.

OMURA, H., 1950. On the body weight of the sperm and sei whales located in the adjacent waters of Japan. Scientific Reports of the Whales Research Institute, 4, 1-13.

PARRY, D. A., 1949. The structure of whale blubber and its thermal properties. Quarterly fournal of Microscopical Science, 90, 13-26.

Pouchet, G. \& Beauregard, H., 1889. Recherches sur le cachelot: anatomie I-V. Nouvelles archives du Muséum d'histoire naturelle, Paris, part 3, pp. 1-96.

RAVEN, H. C. \& GREGORY, W. K., 1933. The spermaceti organ and nasal passages of the sperm. whale (Physeter catodon) and other odontocetes. American Museum Novitates, 677, 1-18.

SchenkKan, E. J. \& PuRves, P. E., 1973. The comparative anatomy of the nasal tract and the function of the spermaceti organ in the Physeteridae (Mammalia, Odontoceti). Bijdragen tot de dierkunde, 43, 93-112.

Scholander, P. F., 1940. Experimental investigations on the respiratory function in diving mammals and birds. Hvalrådets skrifter, 22, 1-131.

SPENCER, M. P., Gornall III, T. A. \& Poulter, T. C., 1967. Respiratory and cardiac activity of killer whales. Fournal of Applied Physiology, 22, 974-981.

Tenney, S. M. \& Remmers, J. C., 1963. Comparative quantitative morphology of the mammalian lung: diffusing area. Nature, London, 197, 54-56.

\section{EXPLANATION OF PLATES}

\section{Plate I}

(A) Posterior face of a transverse section of the case with spermaceti tissue. Rule $=2.5 \mathrm{~cm}$ wide.

(B) Longitudinal section showing spermaceti oil tissue lying within the case. Blubber $=12 \mathrm{~cm}$ thick.

Abbreviations. bl, blubber; cs, case; i, muscle insertions; ln, left naris; mm, maxillonasalis muscle; $\mathrm{rn}$, right naris; $\mathrm{s}$, spermaceti tissue of sac; $t$, tendons.

\section{Plate II}

(A) Longitudinal slice of the junk of an adult showing division of the spermaceti tissue into blocks. Anterior end to the left.

(B) Horizontal section of the anterior end of the head of a sperm whale adult. The cut surface exposes the dorsal end of the blocks of spermaceti tissue in the anterior junk (to the right). The most anterior blocks were dark red (black in photograph) showing distension of blood vessels in the region.

(c) Transverse section of the posterior end of the spermaceti organ and the skull of a large whale. The ventral side of the skull is to the left.

Abbreviations. s, Spermaceti sac; sk, skull. 